C.P. Warlow, M.S. Dennis, J. Van Gijn, G.J. Hankey, P.A.G. Sandercock, J.M. Bamford, J. Wardlaw

\section{Stroke: A Practical Guide to Management}

Blackwell, Oxford 1996

664 pp.; GBP 99.50

ISBN 0-86542-874-3

The headlines of the first nine chapters about diagnosis of stroke are formulated as questions: 'Where is the lesion? What pathological type of stroke is it?', etc. The second nine chapters are dedicated to the management of stroke, intracerebral haemorrhage, and subarachnoidal haemorrhage, which include also chapters about stroke prevention and public health problems with stroke patients.

In the Introduction are aims and scope of the book, and its use is explained. This part, amusing to read, convinces the reader that the authors are practicing doctors who work with stroke patients in their day-to-day practice. The authors think that their book is not an encyclopedia of stroke, but a helpful reference, when a stroke problem arises and an immediate decision is needed.

The different first chapters give clear answers in all diagnostic questions. Many subheadings and important statements, given in a gray box, improve transparency and readability of the text. The didactic form must be simply marked as magnificent. If the reader, however - sorry to say -, comes to the chapter of treatment of acute stroke, the book suddenly becomes fairly disappointing. It is simply impossible to find a practical guide or at least an approach for stroke management as promised in the title of the book. Only a listing of therapeutic principles is given which the authors do not recommend in stroke therapy. The referee read this chapter three times to find at least a single notice what to do with a patient who had a stroke just $1 \mathrm{~h}$ before admission to the hospital, but not a single advise is given. Is it really helpful to the patient to do in acute stroke nothing? What a book in which the key topic 'management of stroke' remains unanswered. If one considers that 8-9 of 10 strokes are ischaemic strokes and no more than 1-2 haemorrhagic strokes, it is not acceptable that the management of the most important form of stroke remains an empty phrase.

In contrast to the former statement, the chapter about stroke rehabilitation is excellently written and full of practical advises how to help the hemiplegic patient. The reader learns how to handle high blood pressure, epileptic seizures, headache, singultus, immobility, venous thromboembolism, urinary problems, faecal incontinence, and constipation; how to avoid pressure sores, spasticity, and contractures, etc. This part is a constructive aid for a rehabilitation hospital but also for the practitioner who has to care for the stroke patient after his release from the hospital. Valuable hints are given how to improve the patients' activities of daily life, toileting, washing, bathing, dressing, and feeding.

In the chapter on prevention of recurrent stroke, the reader learns that myocardial infarction is often a more likely cause of death than a second stroke. Even this part gives a series of helpful recommendations how to avoid a progression of stroke. Practical proposals about the organization of stroke services are given.

A last chapter concerns epidemiological data about stroke incidence and mortality.
The book is a particularly helpful tool in the management of a manifest brain infarction or an intracerebral haemorrhage, except the treatment of acute ischaemic stroke. A new edition needs urgently a clear statement what to do in the situation of an acute ischaemic stroke by the practitioner and finally by the clinician. One has the impression that in the chapter about management of acute stroke the authors had difficulties to distinguish the wood from the trees.

In spite of these critical remarks, the seven-author monograph is a remarkable piece of work with a complete compensation to any vanity of a single author. The book is written in a brilliant didactic form, in particular in the diagnostic part. But also the neurosurgery related indications of stroke therapy and the chapter on stroke rehabilitation have a well-balanced presentation.

W. Meier-Ruge, Basel

\section{J. Gu (ed) \\ Analytical Morphology: Theory, Applications and Protocols}

ICG Publications 1996

Hardcover Edition, Birkhäuser, Boston, Mass., USA

264 pp.; 31 colorplates; CHF 178.00

ISBN 0-8176-3957-8

This book consists of 12 chapters written by different authors. Most of the chapters provide a detailed description of some new techniques for improving existing methods for staining and morphological analysis. Highlights include a chapter about antigen retrieval techniques and an improved technique for eliminating background staining in immunohistochemistry, particularly on tissue from species in which antibodies were made. In-depth discussion of routine details such as the use of microwave ovens for antigen retrieval technique is very useful. Three chapters on various techniques and applications of in situ hybridization including fluorescence in situ hybridization (FISH) provide the readers with both sufficient details and an overview of the methodology. Most chapters also include a brief summary of the development of the field and provide sufficient references, thus meeting the expectations - Theory, Applications and Protocols - from the title of the book.

The book is primarily oriented towards analytical morphology in pathology and diagnostics, although - as the editor points out - it goes beyond routine techniques (e.g. chapter on confocal microscopy). The book, however, is less comprehensive for research-oriented approaches aside from a chapter on tracing methods. Additional discussion of quantitative morphology would have been helpful, in particular the recent application of unbiased stereology to pathology and diagnostics. The book also lacks a chapter on ultrastructural analysis. The color-plates are all combined in an addendum at the end of the book, making the reading of the text somewhat less enjoyable. Overall, this book is a nice and useful update on morphology and related techniques in pathology and diagnostics.

Mathias Jucker and Michael E. Calhoun, Basel

\section{KARGER}

Fax + 41613061234

E-Mail karger@karger.ch

www.karger.com
(C) 1998 S. Karger AG, Basel

0304-324X/98/0446-0353\$15.00/0

Accessible online at:

http://BioMedNet.com/karger 
Philip Seed, Greg Lloyd

Quality of Life

Jessica Kingsley Publications, London 1997

200 pp.; GBP 14.95

ISBN 1-85302-413-9

The book explores popular references to a popular phrase - 'quality of life'. It is thought to help professionals in health care, welfare, leisure services and in economic and social planning to think more carefully about the services they provide. The authors make an attempt to cover this difficult topic comprehensively by comparing its technical meanings in both medicine and in the social sciences. Methods of measuring quality-of-life parameters in these and other fields are reviewed and an attempt of a holistic approach to this very complex issue is made. The book is divided into five parts: Part 1 explores what quality of life means; Part 2 identifies the emerging values with which it is associated and reveals some surprising changes that have taken place with regard to values over the past few decades; Part 3 applies the values to different areas of social policy; Part 4 considers how quality of life can be measured, and Part 5 explores some wider implications for major institutions in society, including the state, pressure groups and the voluntary sector, as well as, more generally, the meaning of corporate behavior. One of the main conclusions is that in spite of the complaints about a lack of morality and the many issues facing contemporary society both in Britain and worldwide, new values associated with quality of life open up a much more optimistic perspective. This optimistic perspective is dampened by the fact that the authors failed to clearly define their moral term 'new value'. How were the 'old values' brought about, why were they able to occupy the feelings and beliefs of the majority of our present population? What makes human subjects feel, think and behave the way they do and what is needed in order to change their feelings, their thoughts and their behavior? Education? Definitely (but this issue is not covered here). Misery, trouble, anguish, sorrow, stress? Definitely (but this is not meant by quality of life). Welfare, public assistance, affluence and whatsoever are considered to improve the quality of life? Not necessarily.

G. Huether, Göttingen exercise, proper nutrition and relaxation are treated in six parts: The first part deals with the general aspects of physical activity, fitness and health. The next section discusses exercise physiology, functional anatomy and biomechanics, but also the energy costs of physical activity. The third part deals with nutrition, body composition and weight management. A further section studies cardiorespiratory function, muscular strength and low-back function, including lowback pain. A major part gives exercise prescription for health and fitness. The last chapter considers exercise programming.

Each part has its own introduction which describes what this section will bring to the reader. The many headings and the reviews on each page give a magnificent transparency of the textbook. An extended index helps to find a topic of particular interest. In addition, a bibliography allows the interested reader to select original papers for further information.

The didactic form of the handbook is outstanding. Each part lists the objectives of the particular chapters. The essential reading is outlined from page to page in a short review.

For lay people are advises given to begin and continue an active life-style. All foreign terms are explained in simple words, helping nonmedical educated people to understand the messages without any information gap.

Also the geriatrician may understand much better the benefits and limits of a physical exercise training for his patients.

A resistance training may attenuate and possibly prevent loss in bone mass and in this way osteoporosis. In addition, exercise is useful in decreasing blood pressure and in improving glucose tolerance.

A particular chapter advises how to prevent injuries by too much activity. It is clearly mentioned that some risk for cardiovascular problems exists with exercise, but the health risk of an inactive lifestyle is much higher.

The important numbers of a moderate-intensity exercise are 30 min per day during 3-4 days.

The handbook of Howley and Franks gives a well-balanced overview about physical exercise for adults and elderly which eliminates all prejudices against physical exercise training. This book is not only a valuable guide for health fitness instructors, but also for interested lay people and geriatricians.

W. Meier-Ruge, Basel

Edward T. Howley, B. Don Franks

Health Fitness Instructor's Handbook, ed. 3

Human Kinetics (Europe), 1997

532 pp., GBP 37.00

ISBN 0-87322-958-4

The handbook of Howley and Franks presents the fundaments of exercise physiology and biomechanics, and is a guideline for safe fitness programs.

This book is primarily written for fitness exercise instructors, but may also help geriatricians to understand how fitness programs work and which effects can be expected. In particular, this book helps to improve the communication between the geriatrician, his patient and the health fitness instructor. All important aspects of regular 